\title{
A PRODUÇÃO ACADÊMICA EM POLÍTICAS EDUCACIONAIS PARA FORMAÇÃO DE PROFESSORES NA EDUCAÇÃO INFANTIL NO BRASIL (2000- 2005)
}

\author{
Andressa Cerqueira Gonçalves ${ }^{1}$; Fani Quitéria Nascimento Rehem ${ }^{2}$ \\ 1. Bolsista PIBIC/FAPESB, Graduanda em Licenciatura em Pedagogia, Universidade Estadual de Feira de Santana, e-mail: \\ andressacg.ag@gmail.com \\ 2. Orientadora, Departamento de Educação, Universidade Estadual de Feira de Santana, e-mail: fanirehem@gmail.com
}

PALAVRAS-CHAVE: Formação de Professores; Educação Infantil; Produção Acadêmica.

\section{INTRODUÇÃO}

O presente trabalho é resultado da pesquisa intitulada "A produção acadêmica em políticas educacionais para formação de professores na Educação Infantil no Brasil (2000-2005)" que tem como objetivo analisar as características das teses e dissertações produzidas no período de 2000 a 2005 nos programas de pós-graduação em educação e identificar as principais tendências dessa produção, em relação às perspectivas de constituição do campo de estudo em políticas educacionais para Formação de Professores na Educação Infantil. O estudo faz parte da pesquisa intitulada "Questões epistemológicas e metodológicas da produção acadêmica em políticas educacionais no Brasil (2000-2010). Como referencial teórico nos fundamentamos nos seguintes autores: Kuhlmann Júnior (1998) e Arce (2001) para discutir a trajetória da educação infantil; Gatti (2010) sobre formação de professores; Arce e Raupp (2012), Martins Filho (2006; 2009), Kishimoto (1999), Santana (2011), Strenzel (2000) para aporte teórico sobre as políticas educacionais para formação de professores na educação infantil; André (1986), Ferreira (2002), Romanowski (2013) sobre a metodologia e abordagem.

\section{MATERIAL E MÉTODOS OU METODOLOGIA}

Este estudo baseia-se em uma abordagem qualitativa visto que se pretende produzir descrições mais densas sobre o objeto de estudo, buscando a obtenção de dados descritivos e em contato maior com a situação estudada. Desse modo, a metodologia utilizada é o estado da arte. Essa forma de pesquisa também é conhecida como estado do conhecimento, que segundo Ferreira (2002), nos últimos anos tem produzido um conjunto significativo de pesquisas, sendo

Definidas como de caráter bibliográfico, elas parecem trazer em comum o desafio de mapear e de discutir uma certa produção acadêmica em diferentes campos do conhecimento, tentando responder que aspectos e dimensões vêm sendo destacados e privilegiados em diferentes épocas e lugares, de que formas e em que condições têm sido produzidas [...](FERREIRA, 2002, p. 258).

Neste sentido, esta escolha comunga com os objetivos delineados em que se pretende analisar as características das produções acadêmicas da pós graduação (teses e dissertações) que tratam de políticas educacionais para Formação de Professores na Educação Infantil. A referida pesquisa envolveu dois momentos: no primeiro realizamos o mapeamento a partir dos seguintes descritores: Formação de Professores, Educação Infantil, Creche e Pré-Escola, identificando aspectos como: autor, orientador, título, palavras-chave, linha de pesquisa, instituição e localização geográfica. No segundo momento, analisamos as tendências e abordagens dessas produções a partir da análise dos resumos apresentados. 


\section{DISCUSSÃO DOS RESULTADOS}

O mapeamento e posteriormente a organização dos dados sobre produções acadêmicas referentes às políticas educacionais para Formação de Professores da Educação Infantil no Brasil (2000-2005) revelou a existência de 6 produções, sendo 3 dissertações de mestrado e 1 tese de doutorado. Após a análise do material, essa quantidade é reduzida para 4 produções, 3 dissertações de mestrado (Rangel, 2003; Rodrigues, 2003; Francisco, 2005) e 1 tese de doutorado (Sales, 2005), conforme o gráfico abaixo:

Quantidade de produções acadêmicas sobre políticas educacionais para Formação de Professores da Educação Infantil no Brasil por ano (2000-2005)

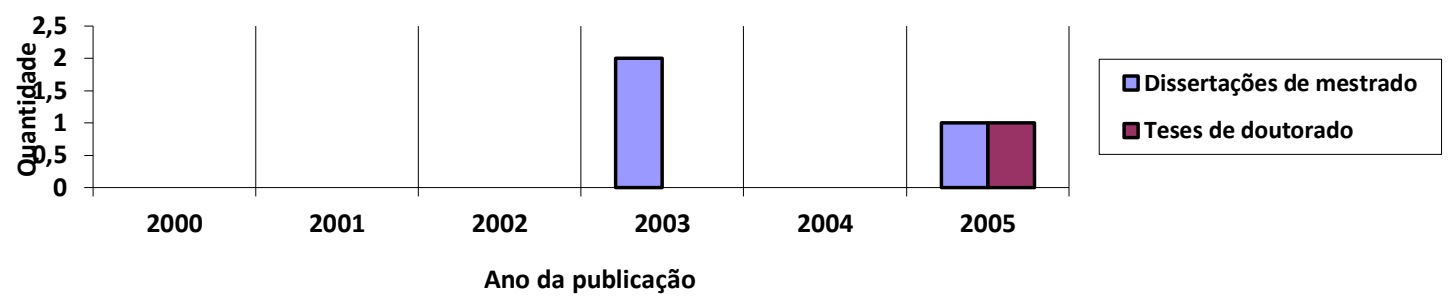

Fonte: Banco de Dados do CEDE. Elaboração própria

Desse modo, é perceptível que as produções nos anos 2000, 2001, 2002 e 2004 são nulas, encontrando apenas 2 produções no ano de 2003 e a mesma quantidade no ano de 2005 . A partir desse achado, opta-se por traçar um comparativo com relação às temáticas de educação infantil e formação de professores:

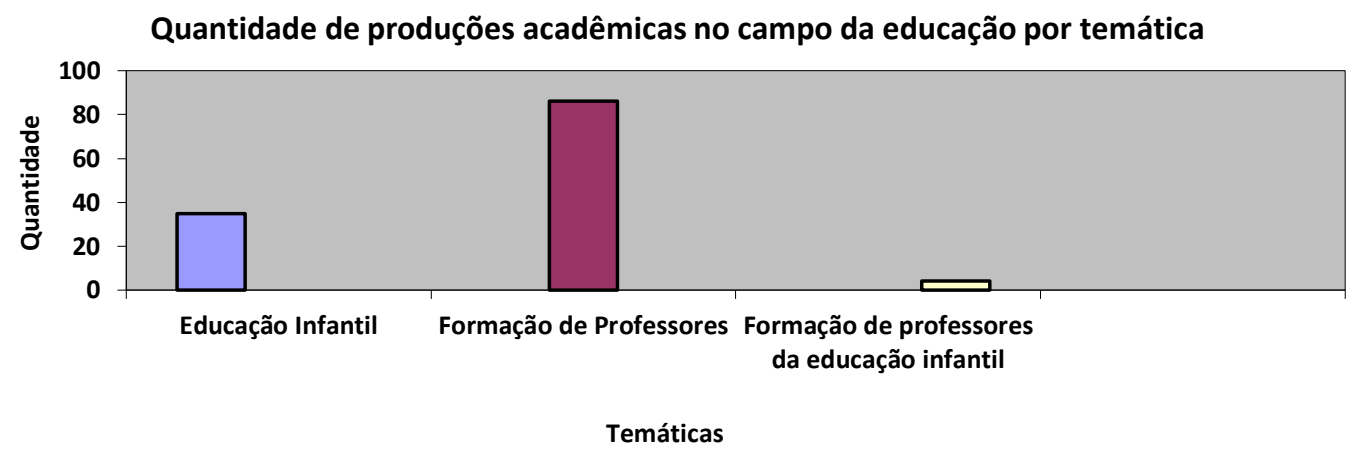

Fonte: Banco de Dados do CEDE. Elaboração própria.

Entende-se que em relação a educação infantil há 35 trabalhos e sobre formação de professores a quantidade é ainda maior, materializando-se em 86 produções. Essa discrepância é alarmante, pois percebe-se a fragilidade teórica do campo de políticas para formação de professores da educação infantil. Segundo Kishimoto (1999, p.64) "Os estudos sobre o curso de pedagogia geralmente tratam de sua identidade e campo de estudo. Há poucas informações históricas sobre seu aparecimento nos anos 30, e menos ainda sobre profissionais de educação infantil”".

A partir desta constatação, vale considerar também que foi após a promulgação da Lei de Diretrizes e Bases da Educação Nacional de 20 de dezembro de 1996 (LDB 9394/96) que a educação infantil fora inserida como primeira etapa na Educação Básica e parafraseando Romanowski (2012) o contexto das políticas públicas interferem diretamente nas produções acadêmicas.

Por isso, entende-se que a discussão sobre as políticas de formação de professores na educação infantil é preterida se comparada aos dois outros temas, fato problematizado por 
Alessandra Arce (2001) em seus estudos sobre o mito da educadora nata, debate que também podemos ver em Kishimoto (1999)

O imaginário popular e até dos meios oficiais pouco afeitos às reflexões sobre a criança e a educação infantil referendam, ainda, a perspectiva romântica do século passado, de que para atuar com crianças de 0 a 6 anos basta ser "mocinha, bonita, alegre e que goste de crianças", e a idéia de que não há necessidade de muitas especificações para instalar escolas infantis para os pequenos. Essa parece ser também a forma de pensar que reina entre membros do atual Conselho Nacional de Educação, refletida nas propostas oficiais que se distanciam de uma formação profissional qualificada (KISHIMOTO, 1999, p.74).

Ou seja, a despreocupação com a referida formação é um fator histórico de completa alienação que insiste em perpetuar no imaginário popular, desqualificando os profissionais que atuam nesta etapa de ensino.

Em relação à localização geográfica das produções, estas encontram-se em instituições da região Sul e Sudeste, especificamente nas seguintes Instituições de Ensinos Superior (IES): Universidade Federal do Rio Grande Do Sul (UFGRS), Universidade Metodista de Piracicaba (UNIMEP), Universidade Federal do Espírito Santo (UFES), Universidade Estadual de Campinas (UNICAMP).

Estes dados são reveladores, pois conforme Silvia e Jacomini (2016) indicam a concentração em algumas regiões e escassez em outras.

é uma situação preocupante, pois[...] indica ampliação da histórica desigualdade de produção de conhecimento entre as regiões do país, reproduzindo o fenômeno em que justamente as regiões que mais necessitam de análises de dados sobre suas condições são as que menos aparecem como objeto de pesquisa (SILVA \& JACOMINI, 2016, p.87).

Neste caso específico, não há produções nas regiões Norte, Nordeste e Centro-Oeste, o que, segundo, Silva (2015) é relevante tendo em vista a concentração dos cursos de pós graduação (mestrado e doutorado) nas regiões Sul e Sudeste na área de Educação e os escores estabelecidos pelo critério da pesquisa anterior que estabeleceu como corte os programas de pós-graduação em educação com nota igual ou superior a 5.

Ao analisar os resumos, verifica-se que estes apresentam algumas insuficiências com relação ao critério que utilizamos como resumos de "qualidade" o que dificultou identificar algumas características pré-estabelecidas. Resumo de "qualidade" é aqui entendido como aquele no qual o autor apresenta o conteúdo temático, os objetivos, o percurso metodológico (metodologia e procedimentos distintos), linha teórica e os resultados encontrados.

Com relação as metodologias utilizadas as produções encontradas com foco na formação de professores na educação infantil no recorte de 2000-2005, aproximadamente 50\% correspondem a estudo de caso e 50\% análise documental. Ainda com base nos resumos, verifica-se que apenas a produção de Rodrigues (2003) analisa o contexto político enquanto as demais fazem uma análise teórico prático a despeito das políticas educacionais para formação de professores da educação infantil, sendo que ainda nesta perspectiva, Francisco (205) correlaciona as referidas políticas ao processo de construção identitária das professoras.

\section{CONSIDERAÇÕES FINAIS}

Através da catalogação das produções acadêmicas e análise dos respectivos resumos, percebe-se a pouca produção com foco na temática políticas educacionais para formação de 
professores na Educação Infantil. Apesar de localizarmos 85 trabalhos que tratam da política de formação de professores, quando direcionamos nosso olhar para a educação infantil isso se transforma em aproximadamente 5\%. A discrepância entre estes números evidencia a relevância do presente estudo e a produções nos instiga as novas pesquisas sobre os anos posteriores. Percebe-se, com os nossos achados a necessidade de estudos que problematizem a política de formação de professores, inquirindo seus objetos, suas concepções de formação e de educação infantil, indicando com isso as lacunas neste campo de estudo.

\section{REFERÊNCIAS}

ARCE, A. Documentação oficial e o mito da educadora nata na educação infantil. Cad.

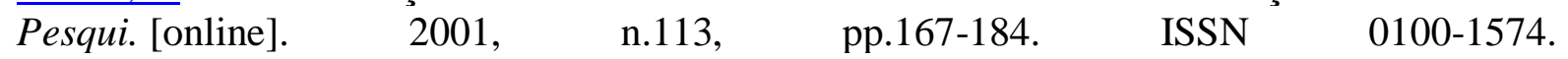
http://dx.doi.org/10.1590/S0100-15742001000200009.

GATTI, B. A. Formação de professores no Brasil: características e problemas. In: Educ. Soc., Campinas, v. 31, n.113, p. 1355-1379, out.-dez. 2010. Disponível em <http:www.cedes.unicamp.br>

FERREIRA, N. S. de A. As pesquisas denominadas "estado da arte". Educ. Soc. [online]. 2002, vol.23, n.79, pp.257-272. ISSN 0101-7330. http://dx.doi.org/10.1590/S010173302002000300013 .

KISHIMOTO, T. M. Política de formação profissional para aeducação infantil: Pedagogia e Normal Superior. IN: Educação \& Sociedade, ano XX, nº 68, Dezembro/99.

KUHLMANN JUNIOR, M. Infância e educação infantil: uma abordagem histórica. Porto Alegre: Mediação, 1998.

LUDKE, Menga e ANDRÉ, Marli. Pesquisa em educação: abordagens qualitativas. São Paulo: E.P.U. 1986.

MARTINS FILHO, A. J. Por uma Pedagogia da Educação Infantil. In: Revista Poíesis Volum 3, Números 3 e 4, pp. 54-65, 2005-2006.

MARTINS FILHO, A. J. Educação Infantil, Formação de Professores e Produção de Conhecimento. In: XII Conferência Anual, 2009, Niterói - RJ.

Pesquisas em políticas educacionais: características e tendências/ Antonia Almeida Silva, Márcia Aparecida Jacomini, organizadoras. - Feira de Santana: UEFS Editora, 201. 227 p.:il. RAUPP, M. D.; ARCE, A. A formação de professores de educação infantil: algumas questões para se pensar a profissional que atuará com crianças de 0 a 3 anos. In: ARCE, Alessandra Martins, M. Ligia. (Org). Ensinando aos pequenos de zero a três anos. 2ed.Campinas: Atomo e Alinea, 2012, v. 01, p.51-92.

ROMANOWSKI, J. P. Apontamentos em pesquisas sobre formaçãode professores: contribuições para o debate. In:Rev. Diálogo Educ., Curitiba, v. 12, n. 37, p. 905-924, set./dez. 2012.

SANTANA, D. R. Infância e educação infantil no Brasil: percursos e percalços. IN: Enciclopédia Biosfera, Centro Científico Conhecer - Goiânia, vol.7, N.12; 2011.

SILVA, Antonia A. A pesquisa em políticas educacionais e sua evolução nos programas de pós-graduação no Brasil: sínteses de um percurso coletivo. Olh@ res. Guarulhos - SP, v. 3, n. 2, p. 34-46, nov. 2015.

STRENZEL, G. R. A Educação Infantil na Produção dos programas de Pós-Graduação em educação no Brasil: indicações pedagógicas para educação de crianças de 0 a 3 anos. Florianópolis, 2000. 220f. Dissertação (Mestrado em Educação). Programa de Pós Graduação em Educação. Universidade Federal de Santa Catarina. 